\title{
Governance im europäischen Forschungsförderverbund
}

Eine rechtswissenschaftliche Analyse der Forschungspolitik und Forschungsförderung im Mehrebenensystem

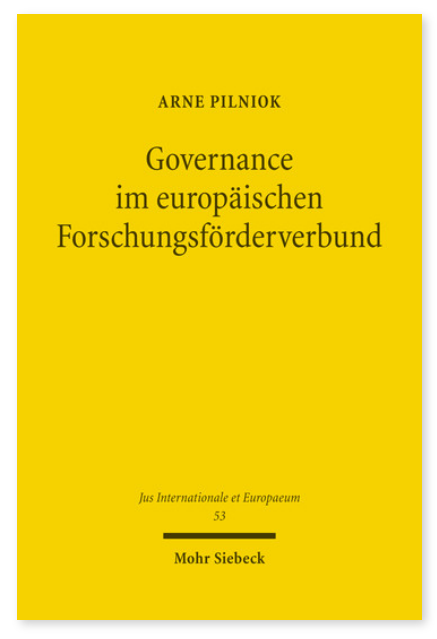

2011. XV, 434 Seiten. JusIntEu 53

ISBN 978-3-16-151191-2

DOI 10.1628/978-3-16-151191-2

eBook PDF $94,00 €$

ISBN 978-3-16-150739-7

fadengeheftete Broschur 94,00€
Der europäische Verwaltungsverbund hat sich in der Rechtswissenschaft als Paradigma etabliert. Arne Pilniok zieht in dieser Perspektive erstmals die Forschungsförderung als Referenzgebiet heran. Er untersucht die Formen der horizontalen und vertikalen Interaktionen innerhalb der Union und zwischen den Mitgliedstaaten in der (öffentlichen) Forschungsförderung. Die Eigenarten des Sachbereichs Forschung, die Kompetenzverteilung zwischen den Ebenen, die administrativen Restriktionen und Wissensprobleme sowie das allgemeine europäische Verwaltungsrecht führen dabei zur Ausprägung einer sachbereichsadäquaten Verbundstruktur: dem europäischen Forschungsförderverbund. Dessen Governance-Strukturen analysiert der Autor eingehend und erörtert anschließend die Probleme, die diese ebenenübergreifenden Regelungsstrukturen im Hinblick auf die demokratische Legitimation und die rechtsstaatlichen Grundprinzipien aufwerfen.

Arne Pilniok ist Juniorprofessor für Öffentliches Recht, Verwaltungswissenschaften und rechtswissenschaftliche Fachdidaktik an der Fakultät für Rechtswissenschaft der Universität Hamburg sowie Vertreter des Lehrstuhls für Öffentliches Recht, insbesondere Verfassungsrecht, und Rechtsphilosophie an der Juristischen Fakultät der Humboldt-Universität zu Berlin.

Jetzt bestellen:

https://mohrsiebeck.com/buch/governance-im-europaeischen-forschungsfoerderverbund-9783161511912?no_cache=1 order@mohrsiebeck.com

Telefon: +49 (0)7071-923-17

Telefax: +49(0)7071-51104 